\title{
LA PARTICIPACIÓN POLÍTICA DE LAS MUJERES: LA LEY DE IGUALDAD 3/2007 DE 22 DE \\ MARZO COMO PUNTO DE PARTIDA PARA ALCANZAR LA IGUALDAD EFECTIVA ENTRE HOMBRES Y MUJERES EN EL ÁMBITO POLÍTICO
}

\author{
Nieves Alonso García \\ nievesalong@gmail.com \\ Universidad de León
}

Recibido: 03-12-2014

Aceptado: 09-04-2015

\section{Resumen}

En el presente trabajo se analiza la participación política de las mujeres, centrándose en el estudio de la Ley Orgánica 3/2007, de 22 de marzo para la igualdad efectiva entre mujeres y hombres y en la normativa electoral autonómica en materia de igualdad. Dentro de la Ley de Igualdad se realiza un estudio, fundamentalmente, de la modificación de la Ley Orgánica del Régimen Electoral General encaminada a conseguir el objetivo de alcanzar una democracia paritaria en la que hombres y mujeres accedan en igualdad de condiciones a los órganos decisorios.

Palabras clave: Participación política, igualdad, paridad electoral, democracia paritaria.

\begin{abstract}
In this paper, the political participation of women is analyzed, focusing on the study of Fundamental Law 3/2007 of 22 March for effective equality between women and men and the autonomic electoral legislation on equality. Within the Equality Act, a study is carried out, mainly, on the modification of the Gerneral Electoral Act aimed at achieving the goal of parity democracy, in which men and women have equal access to decision-making bodies.
\end{abstract}

Keywords: Political participation, equality, electoral parity, parity democracy. 


\section{Introducción}

El derecho a la participación política de las mujeres ha estado muy limitado en la historia política. Tradicionalmente, la sociedad se fundaba en la supremacía patriarcal, lo que fomentó a lo largo de la historia que las mujeres vieran limitados sus derechos tanto en su vida privada como en la pública.

A lo largo del siglo XX surgió con fuerza la lucha de las mujeres por reivindicar el reconocimiento de sus derechos en todos los ámbitos de su vida pública y privada.

Clara Campoamor, impulsora del derecho a voto de las mujeres durante la II República Española defendía que "sin las mujeres no hay democracia, y quienes nos acusan de no estar preparadas, olvidan que la democracia es una asignatura que sólo se aprende ejercitándola" (Lousana Arochena, 2014: 72).

Es en el seno de la Conferencia de Atenas de $1992^{1}$ en el que se acuña el término de democracia paritaria y se reclama la igualdad entre hombres y mujeres en todos los ámbitos de la sociedad. En la citada Cumbre se defendió que "las mujeres constituyen la mitad de las inteligencias y de las capacidades potenciales de la humanidad y su infrarrepresentación en los puestos de decisión constituye una pérdida para el conjunto de la sociedad" (Bengoechea, 2010:161).

La IV Conferencia ministerial europea sobre igualdad entre hombres y mujeres, celebrada en Estambul el 13 y 14 de noviembre de 1997, puso de manifiesto que para la realización de una democracia verdadera ya no puede permitirse ignorar las competencias, las aptitudes y la creatividad de las mujeres.

En el presente artículo y a los efectos de acotar el amplio margen de análisis que supondría el estudio pormenorizado de la defensa de la igualdad efectiva entre hombres y mujeres en los distintos ámbitos, procederé a centrarme en destacar el reto del legislador español de alcanzar la igualdad dentro del ámbito político, a través fundamentalmente de la modificación de la Ley Orgánica 5/1985, de 19 de junio, de Régimen Electoral encaminada a establecer la paridad en las listas electorales.

\footnotetext{
${ }^{1}$ El 3 de noviembre de 1992 se celebró en Atenas a convocatoria de las Comisión de las Comunidades Europeas una cumbre de mujeres en el poder en la cual estaban convocadas mujeres con experiencia en altas responsabilidades políticas.
} 
En primer lugar, se realizará una síntesis de la evolución histórica de la participación política de las mujeres en España, tanto como partícipes en el derecho a voto como en la integración en los órganos decisorios. En esta evolución estará muy presente la influencia ejercida por las instituciones supraestatales, y especialmente desde el ordenamiento comunitario.

En segundo lugar, se llevará a cabo un análisis de la Ley 3/2007, de 22 de marzo para la igualdad efectiva entre mujeres y hombres, así como de la normativa electoral autonómica en materia de igualdad.

Dentro del análisis de la Ley de Igualdad se sinterizarán las principales críticas que ha generado desde algunos sectores doctrinales.

Finalmente, se realizará un estudio de los principales fundamentos jurídicos de la Sentencia 10/2008 en la que el Tribunal Constitucional declara la constitucionalidad de la Ley de Igualdad, contra la cual se interpuso un recurso y una cuestión de inconstitucionalidad.

\section{Evolución histórica de la participación política de las mujeres en España}

Las mujeres han reclamado su participación política desde el mismo momento en que se proclama la igualdad para todos los hombres, en tanto en cuanto, sólo hacía referencia a los hombres entendiendo por tal exclusivamente al género masculino.

Una de las principales reivindicaciones fue la concesión del derecho de sufragio. En nuestro país destaca en este ámbito la figura de Clara Campoamor, impulsora del voto femenino, quien defendió y propició la concesión del derecho a voto a las mujeres en la Constitución de la II República Española de 1931. En la citada Constitución, no sólo es significativo en materia de igualdad entre hombres y mujeres el reconocimiento del derecho a voto de las mujeres, consagrado en el artículo $36^{2}$, sino que se introducen disposiciones

\footnotetext{
${ }^{2}$ Artículo 36 del Constitución de 1931: los ciudadanos de uno y otro sexo, mayores de veintitrés años, tendrán los mismos derechos electorales conforme a lo que determinen las leyes.
} 
encaminadas a garantizar el acceso a las mujeres a los cargos públicos ${ }^{3}$ y a los órganos decisorios ${ }^{4}$.

Tras la Guerra Civil y con la instauración de la Dictadura Franquista se inicia un régimen de confesa inspiración paternalista, basado, tal y como sostenía Pilar Primo de Rivera, líder de la Sección Femenina de la Falange Española, en la idea de que:

"el verdadero deber de las mujeres para con la Patria es formar familias con una base exacta de austeridad y de alegría en donde se fomente todo lo tradicional, lo que no haremos nunca es ponerlas en competencia con ellos porque jamás llegarán a igualarlos y en cambio perderán toda la elegancia y toda la gracia indispensable para la convivencia” (Lousada Arochena, 2014:86).

El período franquista supone una involución en materia de igualdad entre hombres y mujeres que no reaparecerá con fuerza hasta la aprobación de la Constitución Española en 1978 ,en la que se reconoce la igualdad de todos los españoles ante la ley, "sin que pueda prevalecer discriminación alguna por razón de nacimiento, sexo, religión, opinión o cualquier otra condición o circunstancia personal o social" (artículo 14) y se contempla la obligación de los poderes públicos de "promover las condiciones para que la libertad y la igualdad del individuo y de los grupos en que se integra sean reales y efectivas" (artículo 9.2 CE).

Desde el orden supraestatal se fueron adoptando resoluciones encaminadas a alcanzar el derecho de las mujeres a la participación política plena, es decir, no sólo el derecho al sufragio activo, sino también a formar parte de los órganos de decisión.

A nivel internacional, cabe destacar la Convención sobre la eliminación de todas las formas de discriminación contra la mujer, de 18 de diciembre de 1979, ratificada por España en 1984, en la que los Estados parte se comprometen a garantizar a las mujeres "en igualdad de condiciones con los hombres, el derecho a participar en la formulación de las políticas gubernamentales y en la ejecución de éstas, y ocupar cargos públicos y ejercer todas las funciones públicas en todos los planos gubernamentales" ${ }^{2}$.

\footnotetext{
${ }^{3}$ Artículo 40 "todos los españoles sin distinción de sexo, son admisibles a los empleos y cargos públicos según su mérito y capacidad, salvo las incompatibilidades que las leyes señalen.

${ }^{4}$ Artículo 53: Serán elegibles para Diputados todos los ciudadanos de la República mayores de veintitrés años sin distinción de sexo ni de estado civil, que reúnan las condiciones fijadas por la Ley Electoral.

${ }^{5}$ Artículo 7 b de la Convención sobre la eliminación de todas las formas de discriminación contra la mujer, de 18 de diciembre de 1979.
} 
La Asamblea General de Naciones Unidas aprobó en 2007 la Resolución 61/145 sobre el seguimiento de la cuarta Conferencia Mundial sobre Mujer y plena aplicación de la declaración y plataforma de Beijing y de los resultados del vigésimo tercero periodo extraordinario de la Asamblea General en la cual considera que "subsisten desafíos y obstáculos a la aplicación de los estándares y normas internacionales para hacer frente a la desigualdad entre el hombre y la mujer" y sigue expresando su preocupación por que aún no se haya alcanzado el objetivo urgente "de la paridad cuantitativa de los sexos en el Sistema de Naciones Unidas, especialmente en categorías superiores". Asimismo, anima a todos los actores a la "adopción de medidas para asegurar la plena representación y participación de la mujer en la toma de decisiones políticas sociales y económicas como condición esencial para la igualdad entre los sexos y el empoderamiento de lo mujer y la niña como factor decisivo para la erradicación de la pobreza".

En este contexto, desde la esfera del Derecho comunitario, y tomando como punto de partida el Convenio Europeo para la protección de los derechos humanos y de las libertades fundamentales, de 4 de noviembre de 1950, la reivindicación de paridad en los órganos decisorios nace en los años 80 impulsada por las actuaciones de las instituciones europeas. La Declaración de Atenas de 1992, constituye el hito que da origen al término "democracia paritaria", pero la búsqueda de la igualdad formal y material entre hombres y mujeres constituye uno de los principales objetivos del Derecho comunitario en el ámbito de los derechos humanos.

Dentro de este marco de actuación, el Consejo de Ministros de la Unión Europea dirige a los Estados miembros la Resolución de 2 de diciembre de 1996 en la cual se encomienda a los mismos que adopten "una estrategia integrada de conjunto destinada a promover la participación equilibrada de las mujeres y de los hombres en los procesos de toma de decisiones y a desarrollar o crear a tal efecto las medidas adecuadas, tales como, en su caso, medidas legislativas, y/o reglamentarias y/o incentivación".

La Carta de Derechos Fundamentales de la Unión Europea consagra una serie de medidas para suprimir las desigualdades entre las que destaca el "fomento de la igualdad de la participación de hombres y mujeres en el proceso decisorio a todos los niveles y en todos los ámbitos, con el fin de aprovechar plenamente todas las capacidades”. 
En esta misma línea, la Resolución de 3 de marzo de 2000 del Parlamento Europeo demanda la "movilización activa de instituciones y órganos representativos nacionales y europeos para contribuir al equilibrio".

El Consejo de Ministros del Consejo de Europa aprobó en 2003 una Recomendación sobre la democracia paritaria "conscientes de que el funcionamiento de los sistemas electorales y el de las instituciones políticas, incluidas los partidos políticos, pueden generar obstáculos a la participación de las mujeres en la vida política y pública..." en la cual animaban a los Estados a llevar a cabo una eventual reforma de las legislaciones a fin de favorecer el derecho a la participación política de las mujeres.

La modificación del Tratado de la Comunidad Europea por el Tratado de Lisboa incluye un nuevo artículo 1 bis, en virtud del cual:

"la Unión se fundamenta en los valores de respeto de la dignidad humana, libertad, democracia, igualdad, Estado de Derecho y respeto de los derechos humanos, incluidos los derechos de las personas pertenecientes a minorías. Estos valores con comunes a los Estados miembros en una sociedad caracterizada por el pluralismo, la no discriminación, la tolerancia, la justicia, la solidaridad y la igualdad entre hombres y mujeres".

Vogel- Polsky (1998) citado por Ventura Romani (2014:45) sostiene que "el acceso de las mujeres a la toma de decisiones es la consecuencia de un principio fundamental, internacionalmente y nacionalmente reconocido, no cuestionado en el plano de la teoría pero que, sin embargo, siempre espera su realización”.

En 2007, a fin de dar cumplimento a las exigencias del Derecho internacional de los derechos humanos, así como al Derecho comunitario y, con la finalidad de garantizar la igualdad efectiva de hombres y mujeres en todos los ámbitos, se aprueba en nuestro país la Ley Orgánica $^{6}$ 3/2007, de 22 de marzo, para la Igualdad Efectiva entre Hombres y Mujeres, que será objeto de análisis en los epígrafes siguientes.

\footnotetext{
${ }^{6}$ Conforme a lo establecido en la Disposición Final Primera, y en referencia al artículo 149 CE, tienen carácter de ley orgánica únicamente las normas comprendidas en las Disposiciones Adicionales Primera, Segunda y Tercera.
} 
Con posterioridad a la entrada en vigor de la Ley, en febrero de 2010, se celebró en Cádiz la III Cumbre Europea de Mujeres en el Poder $^{7}$ en la que se apunta que "la igualdad entre hombres y mujeres no es solo una cuestión de derechos fundamentales y de justicia social, sino que también es una condición previa para lograr los objetivos en materia de crecimiento sostenible, empleo, competitividad, excelencia científica y cohesión social”.

\section{La Ley de Igualdad 3/2007 de 22 de Marzo, para la igualdad efectiva de hombres y mujeres}

\subsection{Fundamento constitucional, justificación y finalidad}

El derecho a la igualdad efectiva entre hombres y mujeres encuentra su fundamentación constitucional en el artículo 14 de la Constitución Española en el que se consagra el derecho a la igualdad y a la no discriminación por razón de sexo, así como en el artículo 9.2 en el cual se establece la obligación de los poderes públicos de promover las condiciones para que la igualdad del individuo y de los grupos en que se integra sea reales y efectivas.

La justificación de la Ley se vincula a las discriminaciones que sufren las mujeres en todos los ámbitos de la sociedad, pero también con un principio democrático: la necesaria incorporación de todas las personas al demos, aumentando los niveles de participación de las mujeres, y con ello, incrementando el aprovechamiento de sus capacidades, lo que debe desembocar en un enriquecimiento de la sociedad española en su conjunta (Ventura, 2014:41).

La Conferencia de Atenas de 1992, citada anteriormente, recoge una importante justificación para la necesidad de la aprobación de una Ley de Igualdad: "las mujeres constituyen la mitad de las inteligencias y de las capacidades potenciales de la humanidad y su infrarrepresentación en los puestos de decisión constituye una pérdida para el conjunto de la sociedad".

Uno de los fines básicos de esta Ley es la participación equilibrada de hombres y mujeres en la toma de decisiones, y en las candidaturas electorales en particular, así como en

\footnotetext{
${ }^{7}$ La III Cumbre Europea de Mujeres en el Poder se celebró en el marco de los eventos para conmemorar el
} bicentenario de las Cortes de Cádiz. 
los cargos públicos de responsabilidad. En la propia Exposición de motivos de la Ley se señala que:

"el llamado en la Ley principio de presencia o composición equilibrada, con el que se trata de asegurar una representación suficientemente significativa de ambas sexos en órganos y cargos de responsabilidad, se lleva así también a la normativa reguladora del régimen electoral general, optando por una fórmula con la flexibilidad adecuada para conciliar las exigencias derivadas de los artículos 9.2 y 14 de la Constitución con las propias del derecho de sufragio pasivo incluido en el artículo 23 del mismo texto constitucional". Se asumen así los recientes textos internacionales en la materia y se avanza en el camino de garantizar una presencia equilibrada de mujeres y hombres en el ámbito de la representación política, con el objetivo fundamental de mejorar la calidad de esa representación y con ella de nuestra propia democracia"

En artículo 1 de la Ley de Igualdad establece como pretensión de la misma hacer efectivo el derecho de igualdad de trato y oportunidades, en particular mediante la eliminación de la discriminación de la mujer, sea cual fuere su circunstancia o condición.

La Ley de Igualdad responde, por tanto a la necesidad invocada desde las instituciones y organismos internacionales y europeos de erradicar la infrarrepresentación de las mujeres en el ámbito político y hacer efectivo el principio de igualdad. La infrarrepresentación de las mujeres en los órganos decisorios impide la inclusión de ideas y valores que aportarían una visión diferente al tener en cuenta a la mujer como sujeto de derechos (Bengoechea, 2010:21).

El Tribunal Constitucional en la Sentencia10/2008 en su fundamento jurídico cuarto, y en relación con la obligación impuesta a los poderes públicos en el artículo 9.2 considera que:

"este precepto constitucional encomienda al legislador la tarea de actualizar y materializar al efectividad de la igualdad que se proyecta, entre otras realidades, en el ámbito de la representación. Del artículo 9.2, y de la interpretación sistemática del conjunto de preceptos constitucionales que inciden en este ámbito, deriva la justificación constitucional de que los cauces e instrumentos establecidos por legislador faciliten la participación de todos los ciudadanos, removiendo, cuando sea preciso, los obstáculos de todo orden, tanto normativos como estrictamente fácticos, que la impidan o la dificulten y promoviendo las condiciones garantizadoras de la igualdad de los ciudadanos. En este punto cabe añadir que la igualdad sustantiva no sólo facilita la participación efectiva de todos en los asuntos públicos, sino que es un elemento definidor de la noción de ciudadanía". 


\subsection{Las disposiciones adicionales Primera y Segunda: La paridad electora}

En el ámbito de la participación política, la Ley de Igualdad lleva a cabo dos importantes modificaciones previstas en las Disposiciones Adicionales Primera y Segunda de la citada Ley.

La Disposición Adicional Primera prevé que "a los efectos de esta Ley, se entenderá por composición equilibrada la presencia de mujeres y hombres de forma que, en el conjunto a que se refiera, las personas de cada sexo no superen el sesenta por ciento ni sean menos del cuarenta por ciento". Tal y como se establece en el precepto, las medidas son bidireccionales, de tal manera que se aplicarán también en el caso de que el sexo predominante fuera el masculino.

El Tribunal Constitucional en la sentencia 12/2008 considera que la composición equilibrada prevista en esta Disposición Adicional Segunda pretendiendo la igual participación efectiva de hombres y mujeres en la integración de las instituciones representativas de un sociedad democrática, no establece una medida de discriminación inversa o compensatoria, favoreciendo a un sexo sobre otro, sino una fórmula de equilibrio entre sexos, que tampoco es estrictamente paritaria, en cuanto que no impone una igualdad entre hombres y mujeres sino la regla de que unos y otras no podrán integrar las candidaturas electorales en un proporción inferior al 40 por ciento. Su efecto, pues es bidireccional, en cuanto que esa proporción se asegura igualmente a uno y otro sexo (FJ 3). Las proporciones se establecen por igual para los candidatos de uno y otro sexo. No se trata de una medida basada en los criterios de mayoría/minoría, sino a atendiendo a un criterio, el sexo, que de manera universal divide a toda sociedad en dos grupos porcentualmente equilibrados (FJ 5).

En la Disposición Adicional Segunda ${ }^{8}$ se introduce una modificación de la Ley Orgánica 5/1985, de 19 de junio, del Régimen Electoral General, introduciendo el artículo 44 bis.

\footnotetext{
${ }^{8}$ Disposición adicional segunda: Modificación de la Ley Orgánica de Régimen Electoral General Se modifica la Ley Orgánica 5/1985, de 19 de junio, del Régimen Electoral General, en los siguientes términos:

Uno. Se añade un nuevo artículo 44 bis, redactado en los siguientes términos:

Artículo 44 bis
}

Cuestiones de género: de la igualdad y la diferencia - e-I.S.S.N: 2444-0221 - No 10, 2015 - pp. 38-56 
En el citado precepto se exige que las candidaturas que se presenten para las elecciones de diputados al Congreso, municipales y de miembros de los consejos insulares y de los cabildos insulares canarios en los términos previstos en esta Ley, diputados al Parlamento Europeo y miembros de las Asambleas Legislativas de las Comunidades Autónomas deberán tener una composición equilibrada de mujeres y hombres, de forma que en el conjunto de la lista los candidatos de cada uno de los sexos supongan como mínimo el cuarenta por ciento.

Se establece, por tanto, un criterio conforme al cual no se favorece en exclusiva al género femenino sino que se exige el equilibrio de cada uno de los sexos estableciendo un

1. Las candidaturas que se presenten para las elecciones de diputados al Congreso, municipales y de miembros de los consejos insulares y de los cabildos insulares canarios en los términos previstos en esta Ley, diputados al Parlamento Europeo y miembros de las Asambleas Legislativas de las Comunidades Autónomas deberán tener una composición equilibrada de mujeres y hombres, de forma que en el conjunto de la lista los candidatos de cada uno de los sexos supongan como mínimo el cuarenta por ciento. Cuando el número de puestos a cubrir sea inferior a cinco, la proporción de mujeres y hombres será lo más cercana posible al equilibrio numérico.

En las elecciones de miembros de las Asambleas Legislativas de las Comunidades Autónomas, las leyes reguladoras de sus respectivos regímenes electorales podrán establecer medidas que favorezcan una mayor presencia de mujeres en las candidaturas que se presenten a las Elecciones de las citadas Asambleas Legislativas.

2. También se mantendrá la proporción mínima del cuarenta por ciento en cada tramo de cinco puestos. Cuando el último tramo de la lista no alcance los cinco puestos, la referida proporción de mujeres y hombres en ese tramo será lo más cercana posible al equilibrio numérico, aunque deberá mantenerse en cualquier caso la proporción exigible respecto del conjunto de la lista.

3. A las listas de suplentes se aplicarán las reglas contenidas en los anteriores apartados.

4. Cuando las candidaturas para el Senado se agrupen en listas, de acuerdo con lo dispuesto en el artículo 171 de esta Ley, tales listas deberán tener igualmente una composición equilibrada de mujeres y hombres, de forma que la proporción de unas y otros sea lo más cercana posible al equilibrio numérico.»

Dos. Se añade un nuevo párrafo al apartado 2 del artículo 187, redactado en los siguientes términos:

Lo previsto en el artículo 44 bis de esta ley no será exigible en las candidaturas que se presenten en los municipios con un número de residentes igual o inferior a 3.000 habitantes.

Tres. Se añade un nuevo párrafo al apartado 3 del artículo 201, redactado en los siguientes términos:

Lo previsto en el artículo 44 bis de esta ley no será exigible en las candidaturas que se presenten en las islas con un número de residentes igual o inferior a 5.000 habitantes.

Cuatro. Se modifica el apartado 2 de la disposición adicional primera, que queda redactado en los siguientes términos:

2. En aplicación de las competencias que la Constitución reserva al Estado se aplican también a las elecciones a Asambleas Legislativas de Comunidades Autónomas convocadas por éstas, los siguientes artículos del título primero de esta Ley Orgánica:

1 al $42 ; 44 ; 44$ bis; $45 ; 46.1,2$, 4, 5, 6 y $8 ; 47.4 ; 49 ; 51.2$ y $3 ; 52 ; 53 ; 54 ; 58 ; 59 ; 60 ; 61 ; 62 ; 63 ; 65 ; 66$; $68 ; 69 ; 70.1$ у $3 ; 72 ; 73 ; 74 ; 75 ; 85 ; 86.1 ; 90 ; 91 ; 92 ; 93 ; 94 ; 95.3 ; 96 ; 103.2 ; 108.2$ y $8 ; 109$ a $119 ; 125$ a $130 ; 131.2 ; 132 ; 135$ a $152 . »$

Cinco. Se añade una nueva disposición transitoria séptima, redactada en los siguientes términos:

En las convocatorias a elecciones municipales que se produzcan antes de 2011, lo previsto en el artículo 44 bis solo será exigible en los municipios con un número de residentes superior a 5.000 habitantes, aplicándose a partir del 1 de enero de ese año la cifra de habitantes prevista en el segundo párrafo del apartado 2 del artículo 187 de la presente Ley. 
mínimo del 40 por ciento, pudiendo verse beneficiado en ese 60 por ciento cualquiera de los sexos.

La obligación de presentar listas con presencia equilibrada se exige a los municipios a partir de 3000 habitantes pero también se establece una moratoria por la que ese tope sólo se aplicará a los municipios de 5000 habitantes a partir de 2011. En las islas se establece el límite de 5000 habitantes.

La Comisión de la Mujer e Igualdad de Oportunidades de representantes de asociaciones de mujeres y los Grupos Parlamentarios de Izquierda Unida-Iniciativa per Catalunya Verds mostraron su disconformidad con el tope de 5000 habitantes por considerarlo excesivamente alto.

A fin de facilitar la aplicación de la Disposición Adicional Segunda, la Junta Electoral Central aprobó una Instrucción en los siguientes términos:

“i. Las listas electorales deben aplicar la composición equilibrada, tanto en el grupo de candidatos, como en las eventuales listas de suplentes, manteniéndose la proporción legal en ambos grupos.

ii. Se reafirmaba el contenido de la Ley de Igualdad en relación con las Comunidades Autónomas.

iii. Que ésta no sería aplicable a las elecciones a las Juntas Generales de los Territorios Históricos que se regirán por su propia normativa al igual que tampoco lo será cuando la Comunidad Autónoma tenga un interés más favorable a la presencia de mujeres.

iv. Que impone que se incluya el Don o Doña junto al nombre de la persona candidata para evitar confusiones y para que quede claro si el nombre corresponde a un hombre o a una mujer" (Ventura y Romaní, 2014:83).

En el artículo 44 bis se establece, por tanto, el requisito del $40 \%$ para cada género en cada tramo de cinco puestos de la lista pero deja a la libre voluntad de los partidos cuál debe ser el orden de los hombres y mujeres en cada tramo.

En la práctica, y teniendo en cuenta que la Ley exige el equilibrio en las listas electorales pero no establece un orden en los puestos, resultaría posible en función de las expectativas electorales beneficiar a uno de los sexos a través de su colocación en los primeros puestos de las $\operatorname{listas}^{9}$. En la mayoría de las circunscripciones ningún partido recibe más de tres

\footnotetext{
${ }^{9}$ Sobre esta problemática consultar: Ramírez y López, 2015.
} 
escaños, por tanto, si todos los partidos iniciaran en todas ellas sus listas con la combinación (Hombre-hombre-hombre-mujer-mujer), ninguna mujer resultaría elegida en esas circunscripciones, y la representación de mujeres en el Congreso sería muy baja.

Asimismo, la Ley de Igualdad, contempla disposiciones encaminadas a alcanzar la igualdad entre hombres y mujeres en el acceso a los cargos públicos.

El artículo $16^{10}$ de la citada Ley regula los nombramientos realizados por los poderes públicos ${ }^{11}$ para que estos procuren atender el principio de presencia equilibrada en los nombramientos y designaciones de los cargos de representación que les correspondan.

En relación con el citado artículo, el legislador se refiere en el artículo $52^{12}$ a los nombramientos de las personas titulares de los órganos directivos de la Administración General del Estado y de los organismos dependientes o vinculados a ella, imponiendo al Gobierno el deber de atender al principio de presencia equilibrada de hombres y mujeres en su designación.

\subsection{La normativa electoral autonómica en materia de igualdad}

A nivel autonómico, se modificaron las leyes electorales a fin de garantizar la paridad electoral. Esta nueva normativa electoral fue recurrida ante el Tribunal Constitucional por el Partido Popular.

En 2002, la Comunidad Autónoma de Baleares ${ }^{13}$ modificó su ley electoral. En ese mismo año, fue modificada la ley electoral de Castilla la Mancha ${ }^{14}$. En ambas legislaciones se proponía la alternancia de mujeres y hombres como requisito en la elaboración de las listas electorales. En estos casos, al igual que en la normativa electoral andaluza, se establecen "listas cremallera", debiendo alternar sucesivamente candidatos de un sexo y el contrario.

\footnotetext{
${ }^{10}$ Artículo 16: Los Poderes Públicos procurarán atender al principio de presencia equilibrada de mujeres y hombres en los nombramientos y designaciones de los cargos de responsabilidad que les correspondan.

${ }^{11}$ La STC 35/1983, de 11 de mayo establece que "la noción de poderes públicos que utiliza nuestra Constitución sirve como concepto genérico que incluye a todos los entes y sus órganos que ejercen un poder de imperio de la soberanía del Estado y procedente en consecuencia a través de una mediación más o menos larga del propio pueblo.

${ }^{12}$ Artículo 52: El Gobierno atenderá al principio de presencia equilibrada de mujeres y hombres en el nombramiento de las personas titulares de los órganos directivos de la Administración General del Estado y de los organismos públicos vinculados a dependientes de ella, considerados en su conjunto, cuya designación le corresponda.

${ }^{13}$ Ley 8/1986, de 26 de noviembre, electoral de la Comunidad Autónoma de Islas Baleares.

${ }^{14}$ Ley 5/1986, de 23 de diciembre, Electoral de Castilla- La Mancha.
} 
En el año 2005, País Vasco y Andalucía ${ }^{15}$ modificaron su legislación electoral. En el caso del País Vasco, se establecía que las candidaturas estuvieran integradas al menos por un 50 por ciento de mujeres y en el conjunto de las listas se hiciera por un tramo de seis. Andalucía optó por el mismo criterio de alternancia que Baleares y Castilla la Mancha, estableciendo en el apartado 1 del artículo 23 que:

\begin{abstract}
"la presentación de candidaturas en la que se alternarán hombres y mujeres, habrá de realizarse entre el decimoquinto y el vigésimo días posteriores a la convocatoria, mediante listas que deben incluir tantos candidatos como escaños a elegir en cada circunscripción y además, cuatro candidatos suplentes, expresándose el orden de colocación entre ellos, ocupando los de un sexo los puestos impares y los del otro los pares".
\end{abstract}

En el ámbito de la paridad en los cargos públicos, la ley electoral de Andalucía fija un mínimo del $40 \%$ de cada sexo ${ }^{16}$ y la del País Vasco obliga al Lendakari a la paridad en el nombramiento del Gobierno ${ }^{17}$.

\title{
3.4. División doctrinal en cuanto a la constitucionalidad de la Ley de Igualdad
}

Desde el momento de su aprobación en 2007, así como durante su tramitación parlamentaria, la Ley Igualdad supuso una división entre quienes sostenían que se imponían medidas inconstitucionales y aquellos que consideraban que no se vulneraban principios constitucionales y defendían la necesidad de su aprobación.

Durante la tramitación de la ley, ciertos sectores políticos consideraban que no era adecuada la imposición legal del equilibrio en las candidaturas electorales ${ }^{18}$, sino que era voluntad de sus partidos políticos garantizar la presencia de mujeres en sus listas.

Asimismo, se introdujeron enmiendas que plantaban como medidas más adecuadas el establecimiento de incentivos que motivaron a los partidos políticos a incluir mujeres en sus listas, como la concesión de mayores subvenciones para los escaños obtenidos por mujeres o

\footnotetext{
${ }^{15}$ Ley $5 / 2005$, de 8 de abril por la que se modifica la Ley $1 / 1986$, de 2 de enero, Electoral de Andalucía.

${ }^{16}$ Ley $18 / 2003$, de 29 de diciembre, por la que se aprueban medidas fiscales y administrativas.

${ }^{17}$ Disposición Final Tercera de la Ley 4/2005, de 18 de febrero, para la Igualdad de Mujeres y Hombres.

${ }^{18}$ Esta postura es defendida, entre otros, por Martínez Alarcón, 2006.
} 
un mayor tiempo gratuito en los medios de comunicación para las candidaturas con mayor equilibrio entre hombres y mujeres ${ }^{19}$.

Un sector doctrinal sostiene que las disposiciones de la Ley de Igualdad vulneran los principios generales de igualdad previstos en la Constitución en los artículos 1.1, 9.2 y 14, el principio de igualdad que rige el acceso a cargos públicos y representativos y el ejercicio del derecho al sufragio activo y pasivo reconocido en los artículos 23.2 y 68.5 de nuestra Carta Magna al establecer el sexo como requisito para ser elegido.

En este mismo sentido, se ha criticado el presunto tratamiento privilegiado que la Ley de Igualdad concede a la mujer frente al hombre, así como su excesivo intervencionismo.

Otro de los argumentos esgrimidos por los sectores más críticos es la vulneración de la libertad de los partidos políticos en relación a su libertad de expresión, ideológica y para formar las candidaturas. Desde este sector doctrinal se sostiene que la paridad electoral impone un límite a la libertad de los partidos políticos para configurar su propia organización y funcionamiento interno. Asimismo, consideran que se limita su libertad ideológica y de expresión, ya que puede haber partidos que defiendan ideales contrarios a la igualdad entre el hombre y la mujer (Rey Martínez, 1999, citado por Molero Martín-Salas, 2008:96).

Siguiendo con esta visión crítica, algunos autores consideraron que el establecimiento de medidas para favorecer la presencia de mujeres en la política podría suponer que otros colectivos reclamaran su cuota de participación.

El sector doctrinal que defiende la constitucionalidad de la Ley de Igualdad se basa, entre otras fundamentaciones, en la jurisprudencia del Tribunal Constitucional que defiende la existencia de medidas de discriminación positiva. En este sentido, se sostiene que la exigencia de igualdad reconoce necesariamente diferenciaciones, careciendo de sentido defender una igualdad absoluta. En el propio concepto de igualdad está inserta la exigencia de que el Derecho lleve a cabo diferenciaciones. La finalidad de la igualdad es que todos han de ser considerados iguales conforme a los mismos parámetros, lo cual no se traduce en que todos debamos ser iguales en todo. De esta manera igualdad no supone igualitarismo, porque éste es una degradación de la igualdad (Bengoechea, 2010:23).

El Tribunal Constitucional declaró la constitucionalidad del artículo 44 bis en la Sentencia 12/2008 de 29 de enero que será objeto de análisis en el siguiente epígrafe.

\footnotetext{
${ }^{19}$ Esta enmienda fue propuesta por la portavoz del Grupo Parlamentario Popular, Susana Camarero.
} 


\subsection{La Sentencia 12/2008: El equilibrio entre sexos como aspecto determinante para la definición del contenido de las normas}

La Ley de Igualdad, tal y como se ha expuesto anteriormente fue objeto de numerosos críticas doctrinales en las que se cuestionaba su constitucionalidad, pero sólo fueron objeto de impugnación ante el Tribunal Constitucional las normas relativas al equilibrio entre hombres y mujeres en las listas electorales.

Desde el ámbito político y como consecuencia de la obligación de paridad impuesta por la Ley de Igualdad, se interpuso una cuestión de inconstitucionalidad ${ }^{20}$ basada en la posible vulneración del artículo 23, en relación con los artículos 6 y 14 de la Constitución Española por la inclusión del artículo 44 bis en la Ley Orgánica 5/1985, de 19 de junio, del Régimen Electoral General, introducido por la Disposición Adicional Segunda.

La Ley de Igualdad no sólo fue objeto de cuestión de inconstitucionalidad sino que también se interpuso un recurso de inconstitucionalidad por más de cincuenta Diputados del Grupo Parlamentario Popular del Congreso de los Diputados en el cual se impugnaban las diferentes modificaciones de la Ley Orgánica del Régimen Electoral General contenidas en la Disposición Adicional Segunda, no sólo la inclusión del artículo 44 bis sino también la modificación de otros preceptos, y en concreto, sus artículos 187.2 y 201.3. Asimismo, se impugnó la Disposición Adicional Primera y la nueva Disposición Transitoria Séptima.

El Tribunal Constitucional acordó acumular el recurso de inconstitucionalidad a la cuestión de inconstitucionalidad $^{21}$.

En su pronunciamiento el Alto Tribunal manifestó que:

"las previsiones del artículo 44 bis no suponen un tratamiento peyorativo de ninguno de los sexos, ya que, en puridad, ni siquiera plasman un tratamiento diferenciado en razón del sexo de los candidatos, habida cuenta de que las proporciones se establecen por igual para los candidatos de uno y otro sexo. No se trata pues de una medida basada en los criterios de mayoría/minoría (como

\footnotetext{
${ }^{20}$ La cuestión de inconstitucionalidad fue planteada por un representante del Partido Popular del municipio de Garachico al que se le niega la proclamación de la candidatura por la Junta Electoral de Zona de Icod de los Vinos al no adaptarse a lo previsto en el artículo 44 bis de la Ley Electoral. Dicho representante político plantea un recurso contencioso-electoral ante el Juzgado de lo Contencioso Administrativo ${ }^{\circ} 1$ de Santa Cruz de Tenerife, planteándose por el Juez titular del mismo una cuestión de inconstitucionalidad ante el Tribunal Constitucional.

${ }^{21}$ Auto de 17 de diciembre de 2007 del Tribunal Constitucional.
} 
sucedería si se tomase en cuenta como elementos de diferenciación, por ejemplo, la raza o sexo) sino atendiendo a un criterio, el sexo, que de manera universal divide a toda sociedad en dos grupos porcentualmente equilibrados" (FJ 5)".

Siguiendo la misma línea argumental de la Conferencia de Atenas de 1992, el Tribunal Constitucional sostiene que lo que se pretende es que la igualdad efectivamente existente en cuanto a la división de la sociedad con arreglo al sexo, no se desvirtúe en los órganos de representación política con la presencia abrumadoramente mayoritaria de uno de ellos. Y para que así sea sostiene que una representación política que se articule desde el presupuesto de la divisoria necesaria de la sociedad en dos sexos es perfectamente constitucional, pues se entiende que ese equilibrio es determinante para la definición del contenido de las normas y actos que hayan de emanar de aquellos órganos.

En su pronunciamiento defiende la legitimidad del equilibrio en las listas sosteniendo que "la igualdad no es sólo un instrumento para facilitar la participación efectiva de todos en los asuntos públicos, sino que incluso se puede vincular como un elemento definidor de la noción de ciudadanía, de tal manera que es legítimo la composición equilibrada para hacer efectiva la igualdad".

Asimismo, consideran la necesidad de la norma con el fin de hacer realidad la igualdad efectiva entre hombres y mujeres en los órganos decisorios, tal y como queda reflejado en el fundamento jurídico quinto:

“exigir de los partidos políticos que cumplan con su condición constitucional de instrumento para la participación política (artículo 6), mediante una integración de sus candidaturas que permita la participación equilibrada de ambos sexos, supone servirse de los partidos para hacer realidad la efectividad en el disfrute de los derechos exigida por el artículo 9.2. Y de hacerlo, además de una manera constitucionalmente lícita, pues con la composición de las Cámaras legislativas o de los Ayuntamientos se asegura la incorporación en los procedimientos normativos y de ejercicio del poder público de las mujeres, que suponen la mitad de la población, en un número significativo. Ello resulta coherente, en definitiva, con el principio democrático que reclama la mayor identidad posible entre gobernantes y gobernados". 


\section{Reflexión Final}

A pesar de la constitucionalización de la igualdad en nuestro país en 1978, y ante la infrarrepresentación de las mujeres en el ámbito político, ha sido necesaria la aprobación en 2007 de una Ley de Igualdad cuyo objetivo principal es garantizar la igualdad efectiva de mujeres y hombres.

Si bien, con la aprobación de la Ley se plasma en la teoría el derecho a la participación política de la mujer, internacionalmente demandado, en la práctica, tal y como demuestran los estudios llevados a cabo en este ámbito, el número de mujeres que ocupan los órganos decisorios es inferior al de los hombres.

Ventura y Romaní realizan un interesante estudio en el que tras su análisis del impacto de la Ley de Igualdad en las elecciones de 2004, 2008 y 2011, demuestran que el porcentaje del $40 \%$ exigido por la Ley se ha convertido en una cuota para las mujeres. La mayoría de las candidaturas al Congreso de los Diputados reservan entre el 40 y el $46 \%$ de las candidaturas a las mujeres, suponiendo un mayor porcentaje representativo el de los hombres en sus listas.

Por lo que respecta al requisito de respeto de los porcentajes en cada tramo de cinco candidatos, permite a las partidos políticos llevar a cabo estrategias para beneficiar a un género sobre el otro. A mi juicio, las listas cremallera, previstas en la normativa electoral de algunas Comunidades Autónomas, garantizan una mayor aproximación a la paridad que las basadas en los tramos de cinco.

La Ley de Igualdad ha logrado el inicio de un proceso hacia la consecución de la participación política plena de las mujeres. No obstante, el porcentaje de hombres que acceden a los órganos decisorios sigue siendo superior al de mujeres. Asimismo, en nuestra historia democrática ninguna mujer ha alcanzado la presidencia del Gobierno a nivel nacional. 


\section{BIBLIOGRAFÍA}

- Bengoechea Gil, Mángeles (2010): La lucha por la igualdad efectiva de mujeres y hombres. Reflexiones y aportaciones de la Ley de Igualdad 3/2007, de 22 de marzo. Madrid: Dykinson.

- Lousada Arochena, José Fernando (2014): El derecho fundamental a la igualdad efectiva de mujeres y hombres, Valencia: Tirant lo Blanch.

- Martínez Alarcón, María Luz (2006), Cuota electoral de mujeres y Derecho Constitucional, Madrid, Congreso de los Diputados.

- Molero Martín Salas, María del Pilar (2008): “Comentario a la Sentencia del Tribunal Constitucional Español 12/2008, de 29 de enero”. Instituto de Investigaciones Jurídicas de la UNAM.

- Ramírez González, Victorino (2015): "Mejora de la paridad de género en el Congreso de los Diputados”. Revista Española de Sociología n²3, pp. 95-116.

- Ventura Franch, Asunción y Romaní Sancho, Lucía (2014): El derecho a la participación política de las mujeres. Resultados de la aplicación de la Ley de igualdad en las elecciones a las Cortes Generales (2004-2008-2011).Valencia: Tirant lo Blanch.

- Constitución Española de 1978. En: BOE núm. 311, de 29 de diciembre de 1978, [en línea] Disponible en: http://www.boe.es/boe/dias/1978/12/29/pdfs/A29313-29424.pdf_[05/11/2014].

- Constitución de la II República Española de 1931, [en línea] Diponible en: http://www.congreso.es/docu/constituciones/1931/1931_cd.pdf [05/11/2014].

- Ley Orgánica 3/2007, de 22 de marzo, para la igualdad efectiva de mujeres y hombres. En BOE núm. 71, de 23 de marzo de 2007, [en línea] Disponible en: http://www.boe.es/boe/dias/2007/03/23/pdfs/A12611-12645.pdf [14/11/2014].

- Ley Orgánica 5/1985, de 19 de junio, del Régimen Electoral General. En BOE núm. 147, de 20 de junio, [en línea] Disponible en: http://www.boe.es/boe/dias/1985/06/20/pdfs/A1911019134.pdf [14/11/2014].

- Carta de Derechos Fundamentales de la Unión Europea. En Diario Oficial de las Comunidades Europeas 2000/C 364/01, de 18 de diciembre de 2000, [en línea] Disponible en: http://www.europarl.europa.eu/charter/pdf/text es.pdf [15/11/2014]. 
- Tratado Constitutivo de la Comunidad Europea. En Diario Oficial de las Comunidades Europeas, $C$ 325/33, de 24 de diciembre de 2002, [en línea] Disponible en: http://www.boe.es/legislacion/enlaces/documentos/ue/Trat_EC_consol.pdf [15/11/2014].

- Recomendación del Consejo de 2 de diciembre de 1996 relativa a la participación equilibrada de las mujeres y de los hombres en los procesos de toma de decisión (96/694/CE), Diario Oficial $n^{\circ}$ L 319 de 10/12/1996, [en línea] Disponible en: http://eur-lex.europa.eu/legalcontent/ES/TXT/?uri=CELEX:31996H0694 [17/11/2014].

- Declaración de Atenas de 1992, II Cumbre Europea de Mujeres en el Poder, [en línea] Disponible en: http://igualdad.us.es/pdf/Docuemta_Otros_Cumbre.pdf [17/11/2014].

- Convención sobre la eliminación de todas las formas de discriminación contra la mujer, de 18 de diciembre de 1979, Instrumento de Ratificación de 16 de diciembre de 1983. En BOE núm. 69, de 21 de marzo de 1984, [en línea] Disponible en: http://www.boe.es/boe/dias/1984/03/21/pdfs/A07715-07720.pdf [17/11/2014].

- Resolución 61/145 aprobada por la Asamblea General de Naciones Unidas sobre el seguimiento de la Cuarta Conferencia Mundial sobre la Mujer y plena aplicación de la Declaración y la Plataforma de Acción de Beijing y de los resultados del vigésimo tercer período extraordinario de sesiones de la Asamblea General, [en línea] Disponible en: http://www.acnur.org/t3/fileadmin/Documentos/BDL/2007/5081.pdf?view=1 [17/11/2014].

- Sentencia 10/2008, de 21 de enero de 2008. En BOE núm. 40, de 15 de febrero de 2008, [en línea] Disponible en:

http://www.tribunalconstitucional.es/fr/jurisprudencia/Pages/Sentencia.aspx?cod=15689 [05/11/2014].

- Auto 471/2007, de 17 de diciembre de 2007 del Tribunal Constitucional [en línea] Disponible en: http://www.tribunalconstitucional.es/fr/jurisprudencia/Pages/Auto.aspx? cod=22265 [05/11/2014]. 